\title{
Soleus H-reflex tests and clinical signs of the upper motor neuron syndrome
}

\author{
J H T M Koelman, L J Bour, A A J Hilgevoord, G J van Bruggen, \\ B W Ongerboer de Visser
}

Soleus H-reflex tests are used for elucidating pathophysiological mechanisms in motor control. The cumulative vibratory inhibition of the soleus H-reflex, the ratio of the reflex to direct muscle potential ( $H$ to $M$ ratio) and the recovery curve of the soleus $H$-reflex were studied in 38 patients with varying signs of the upper motor neuron syndrome for a possible relation with clinical features. The results were compared with those obtained from a group of healthy volunteers. The magnitude of vibratory inhibition decreased with increase of hypertonia. The $H$ to $M$ ratio increased as the activity of the tendon reflex was enhanced and correlated to a lesser degree with muscle tone. Both the $H$ to $M$ ratio and late facilitation of the soleus $H$-reflex recovery curve were elevated in clonus. The findings suggest that alterations in the results of soleus H-reflex tests relate to specific clinical features of the upper motor neuron syndrome. Possible pathophysiological implications are discussed.

\section{(F Neurol Neurosurg Psychiatry 1993;56:776-781)}

The H-reflex is evoked by stimulation of $1 \mathrm{a}$ fibres from muscle spindles and appears at lower stimulus intensities and at longer latency than a direct muscle potential evoked by stimulation of motor nerve fibres. ${ }^{1}$ Different soleus H-reflex tests may be used for the study of central mechanisms in motor control of the leg. ${ }^{2}$ In the upper motor neuron syndrome various alterations of these tests are found. Compared with healthy controls suppression of the $\mathrm{H}$-reflex during vibration is decreased in most patients whereas the ratio between the maximal soleus $\mathrm{H}$-reflex response and muscle potential ( $\mathrm{H}$ to $\mathrm{M}$ ratio) is increased..$^{3-5}$ Furthermore, changes in the $\mathrm{H}$-reflex recovery curve obtained by paired stimuli to the posterior tibial nerve are found. ${ }^{67}$ In the upper motor neuron syndrome the various clinical characteristics, such as weakness, loss of dexterity, hyperreflexia, clonus, hypertonia, and the extensor plantar response, may occur independently and in different combinations to a large extent. ${ }^{8}$ As such, a relation between specific clinical features and alterations in the results of $\mathrm{H}$-reflex tests may further contribute in elucidating underlying pathophysiological mechanisms. The relation between the various clinical signs and these neurophysiological alterations, however, is largely unknown or in some cases conflicting. ${ }^{24} \mathrm{We}$ investigated whether in a heterogeneous group of patients with an upper motor neuron syndrome changes in vibratory inhibition of the soleus $\mathrm{H}$-reflex, $\mathrm{H}$ to $\mathrm{M}$ ratio, and the recovery curve of the reflex were related to specific clinical features.

\section{Subjects and methods}

Thirty eight selected patients aged 18-75 years (mean 47 years) participated in the study. Evident clinical features of an upper motor neuron lesion were present in the lower limb, with or without upper motor neuron signs in the upper limb. None of the patients had a lower motor neuron component to their disease. Nine patients had a cerebral lesion: ischaemic infarction in six; arteriovenous malformation in one; infantile encephalopathy in one; and penetrating head injury in one. Fifteen patients had a myelopathy: slowly progressive multiple sclerosis in five; transverse myelitis in two; cervical spondylosis in three; traumatic myelopathy in three; and two intradural spinal meningeoma in two. Fourteen patients had a clinical picture of a slowly progressive spastic paraparesis, seven with a positive family history. Duration of the disease varied from two months to 45 years (mean 7.5 years). The control group consisted of 48 healthy subjects aged $20-70$ years (mean 38 years).

At the time of investigation none of the patients had received medical treatment known to influence spasticity. All subjects gave informed consent. The clinical examination was performed just before the neurophysiological testing. Clinical examination and neurophysiological testing were performed independently by different investigators.

Clinical examination consisted of the assessment of four elementary features of the upper motor neuron syndrome-that is, hypertonia, muscle strength, tendon reflex activity, and the plantar response. Presence and severity of signs were categorised in a standardised fashion. An increase in calf muscle tone was investigated by passive dorsiflexion of the ankle joint and was graded according to the Ashworth scale': 0-normal tone; 1-slightly increased tone giving a catch on abrupt passive stretch of the triceps surae muscle; 2-increased tone; 3-severely increased tone; and 4-passive movement of the ankle joint hardly possible. Strength of 
triceps surae was judged according to the Medical Research Council scale ${ }^{10}$ and graded in four categories: 0-normal (MRC 5); 1slight weakness (MRC 4); 2-moderate weakness (MRC 2 or 3); and 3-severe weakness (MRC 0 or 1). Achilles tendon reflexes were graded as 0 -diminished or absent; 1-normal; 2-increased; 3-ankle clonus (that is, four reflex contractions or more produced by tendon percussion or abrupt ankle dorsiflexion). Plantar reflexes were graded as $\mathbf{0 - f l e x o r ; ~ 1 - ~}$ equivocal; and 2-extensor.

\section{EXPERIMENTAL PROCEDURE}

Recording and stimulation techniques for the soleus H-reflex have been described previously. ${ }^{511}$ During all tests subjects were seated in a reclining chair in a standardised position. ${ }^{5}$ $\mathrm{H}$-reflexes were elicited only when no soleus activity was detected by electromyography. Reflex responses elicited by $1 \mathrm{~ms}$ square current pulses to the posterior tibial nerve in the popliteal fossa were amplified with a band pass filter of $-3 \mathrm{~dB}$ at $2 \mathrm{~Hz}$ and $10 \mathrm{kHz}$ and digitally stored in a PDP 11/73 minicomputer with a sample frequency of $10 \mathrm{kHz}$. The time interval between successive recordings was at least 30 seconds. ${ }^{512}$ For the construction of an $\mathrm{H}$-reflex recruitment curve as a function of stimulus intensity (figure 1a) the increment in

Figure 1 Example of results of soleus $H$-reflex test in patient No 38 (table 1). (a) Recruitment curves of soleus $H$-reflex response $(H)$ and muscle (M) potential (peak-peak values) without vibration of Achilles tendon and with vibration, producing only slight $H$-reflex suppression. All values expressed as percentages of maximum $M$ potential. (b)

Cumulative vibratory effect on H-reflex (peakpeak values) as function of stimulus intensity. Amount of suppression is equal to $100 \%$ minus cumulative vibratory index.
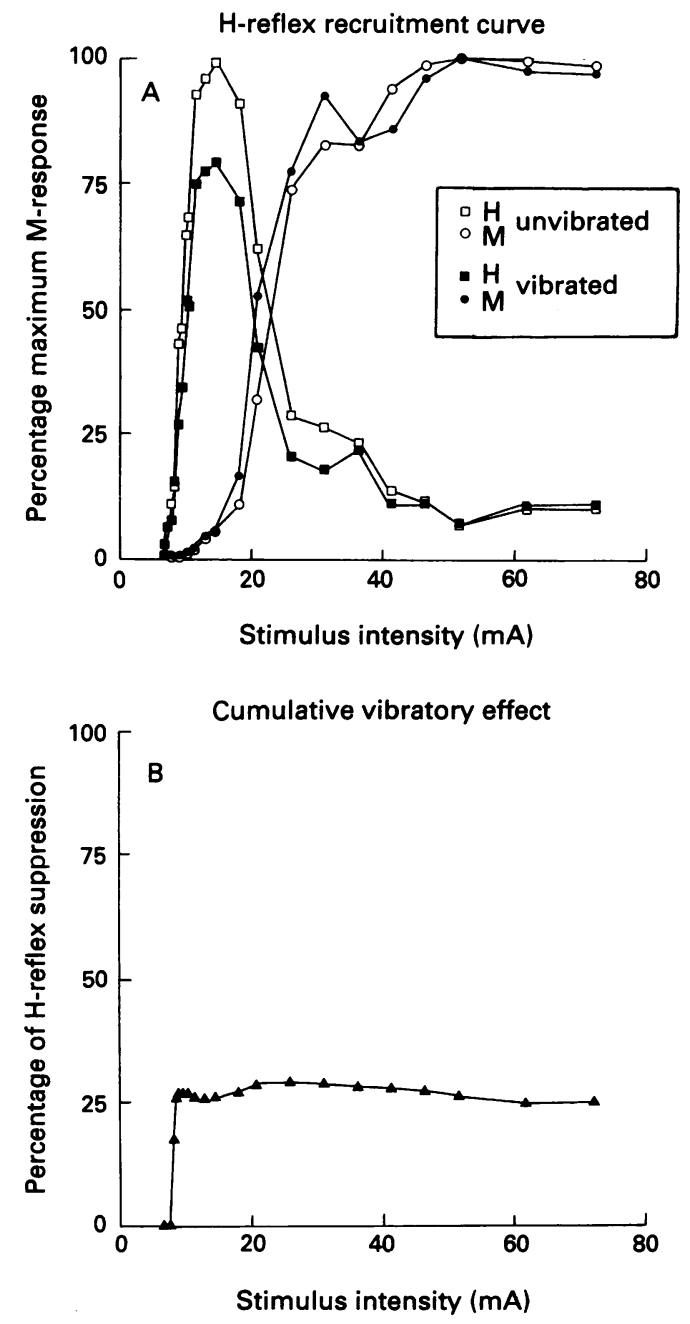

intensity of successive stimuli was small at low intensities but gradually enlarged at higher intensities. Each recruitment curve consisted of 12 or more $\mathrm{H}$-reflexes at different intensities. Simultaneously with the H-reflex recruitment curve, a recruitment curve of direct soleus muscle potentials was constructed also as a function of stimulus intensity (figure 1a). Peak-peak values of the maximum H-reflex response and maximum muscle potential were used to calculate the $\mathrm{H}$ to $M$ ratio.

Vibration of the Achilles tendon with a frequency of $100 \mathrm{~Hz}$ and an undamped amplitude of $1 \mathrm{~mm}$ was applied by a Brüell and Kjær 4809 vibrator. The cumulative vibratory index was used as a quantitative measure for the vibratory effects on the $\mathrm{H}$-reflex (figure 1b). ${ }^{5}$ This index was defined as the surface under the $\mathrm{H}$-reflex recruitment curve obtained during vibration up to a certain stimulus intensity divided by the surface under the $\mathrm{H}$-reflex recruitment curve obtained without vibration up to the same stimulus intensity times $100 \%$. The index at the stimulus intensity that yielded the maximum $\mathrm{H}$-reflex response was used in the calculations. ${ }^{7}$

H-reflex recovery curves were constructed by application of paired pulses of equal intensity. The stimulus intensity at which the $\mathrm{H}$-reflex reached half its maximum value was used (figure 2). ${ }^{7}$ Time intervals between conditioning and test stimuli were 100,200 , $250,300,400$, and $500 \mathrm{~ms}$ and at 1, 3, 10, and 30 seconds. Early facilitation and inhibition were not examined. The recovery curves were plotted as the ratio in percentage between the area values of the test and the conditioning H-reflex response against the time interval between the two stimuli. Two characteristic values were used for statistical analysis: firstly, the local maximum of the test H-reflex occurring in the late facilitatory

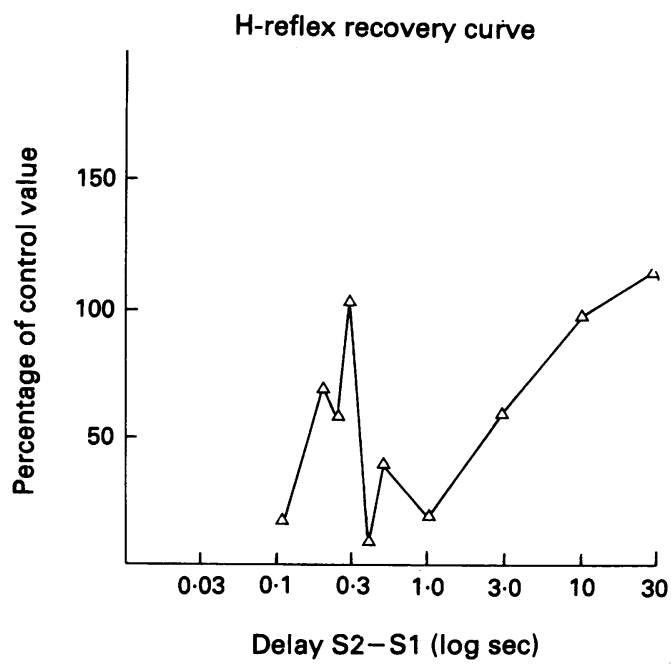

Figure 2 Recovery curve of soleus $H$-reflex response (area values) at $0.5 \mathrm{H}$ maximal stimulus intensity in patient No 38 (table 1). All values of reflex response to test stimulus (S2) presented as percentages of preceding $H$ reflex to conditioning (S1) stimulus. In facilitatory period test reflex reached $100 \%$ of conditioning H-reflex. 
phase at a stimulus time interval ranging from 50 to $320 \mathrm{~ms}$ and, secondly, the local minimum of the test H-reflex found in the late inhibitory phase of the recovery curve at a stimulus time interval ranging from 320 to $1000 \mathrm{~ms}$.

Variables of the soleus H-reflex tests used have previously been shown to discriminate most productively between patients with upper motor neuron lesions and control subjects. ${ }^{7}$

STATISTICAL ANALYSIS

Analysis of variance (BMDP statistical software package $7 \mathrm{D}$ ) was performed with use of a priori contrasts tests for studying correlation between clinical signs and neurophysiological data in patients. Differences in neurophysiological variables in the different groups of patients were examined with pairwise $t$ tests, significance levels were adjusted for the number of paired comparison tests (Bonferroni). Within the groups of patients linear (stepwise) regression analysis (BMDP $1 \mathrm{R}, 2 \mathrm{R}$ ) was performed to examine correlation between neurophysiological variables and between neurophysiological variables and age.

\section{Results}

CLINICAL SIGNS

Table 1 shows the results of the clinical assessment in the patients. Sixteen patients showed a mild clinical picture of an upper motor neuron lesion with normal strength (0, MRC 5) or slight weakness (1, MRC 4) combined with normal or slightly elevated muscle tone (Ashworth 0 or 1). Of these patients plantar responses were extensor in 13, equivocal in two, and flexor in one; clonus was present in three and absent in 13. Seven patients showed a severe clinical picture with moderate (2, MRC 2 or 3$)$ or severe paresis (3, MRC 0 or 1 ) combined with severely increased tone (Ashworth 3 or 4). Plantar responses were extensor in six and equivocal in one, and clonus was present in four and absent in three patients. The 15 other patients had a clinical picture inbetween the former two groups, with plantar responses extensor in 13 and flexor in two. In the patients as a whole the following clinical characteristics were found: tone was normal (Ashworth 0) in six, slightly elevated (Ashworth 1) in 13, moderately elevated (Ashworth 2) in 11, strongly elevated (Ashworth 3) in six, and passive movement was hardly possible (Ashworth 4) in two patients. For statistical analysis patients with Ashworth 3 and 4 were combined because of the small number with Ashworth 4. Strength was normal (0, MRC 5) in 14 patients, weakness was slight $(1, M R C 4)$ in nine, moderate $(2$, MRC 2 or 3$)$ in 11 , and severe (3, MRC 0 or 1 ) in four patients. Tendon reflexes were normal in 12 , increased in 13 , and there was clonus in 13 patients. Plantar responses were extensor in 32 , equivocal in only three, and

Table 1 Clinical signs and results of soleus $H$-reflex tests in patients with the upper motor neuron syndrome

\begin{tabular}{|c|c|c|c|c|c|c|c|c|c|c|}
\hline Patient & $\begin{array}{l}\text { Age } \\
\text { (years) }\end{array}$ & Lesion ^ & $\begin{array}{l}\text { Muscle† } \\
\text { strength }\end{array}$ & $\begin{array}{l}\text { Tendon } \ddagger \\
\text { reflex }\end{array}$ & $\begin{array}{l}\text { Muscle } \\
\text { tone } \\
\text { (Ashworth) }\end{array}$ & $\begin{array}{l}\text { Plantars } \\
\text { response }\end{array}$ & $\begin{array}{l}H \text { to } M \\
\text { ratio } \\
\text { (\%) }\end{array}$ & $\begin{array}{l}\text { Cumulative } \\
\text { vibratory } \\
\text { index } \\
(\%)\end{array}$ & $\begin{array}{l}\text { Late } \\
\text { facilitation } \\
(\%)\end{array}$ & $\begin{array}{l}\text { Late } \\
\text { inhibition } \\
(\%)\end{array}$ \\
\hline $\begin{array}{l}1 \\
2 \\
3 \\
4 \\
5 \\
6 \\
7 \\
8 \\
9 \\
10 \\
11 \\
12 \\
13 \\
14 \\
15 \\
16 \\
17 \\
18 \\
19 \\
20 \\
21 \\
22 \\
23 \\
24 \\
25 \\
26 \\
27 \\
28 \\
29 \\
30 \\
31 \\
32 \\
33 \\
34 \\
35 \\
36 \\
37 \\
38\end{array}$ & $\begin{array}{l}25 \\
41 \\
47 \\
59 \\
27 \\
59 \\
37 \\
39 \\
34 \\
55 \\
75 \\
69 \\
33 \\
50 \\
64 \\
50 \\
57 \\
65 \\
67 \\
59 \\
18 \\
25 \\
61 \\
22 \\
31 \\
50 \\
44 \\
49 \\
51 \\
52 \\
74 \\
52 \\
44 \\
45 \\
50 \\
43 \\
31 \\
59\end{array}$ & $\begin{array}{l}1 \\
1 \\
1 \\
1 \\
1 \\
1 \\
1 \\
1 \\
1 \\
1 \\
1 \\
1 \\
1 \\
1 \\
1 \\
2 \\
2 \\
2 \\
2 \\
2 \\
2 \\
2 \\
2 \\
2 \\
3 \\
3 \\
3 \\
3 \\
3 \\
3 \\
3 \\
3 \\
3 \\
3 \\
3 \\
3 \\
3 \\
3\end{array}$ & $\begin{array}{l}0 \\
2 \\
2 \\
1 \\
3 \\
1 \\
2 \\
1 \\
3 \\
2 \\
2 \\
2 \\
1 \\
0 \\
0 \\
2 \\
3 \\
0 \\
2 \\
3 \\
2 \\
1 \\
1 \\
0 \\
2 \\
0 \\
0 \\
0 \\
2 \\
0 \\
1 \\
1 \\
0 \\
0 \\
1 \\
0 \\
0 \\
0\end{array}$ & $\begin{array}{l}2 \\
2 \\
2 \\
3 \\
3 \\
1 \\
3 \\
2 \\
2 \\
2 \\
1 \\
1 \\
2 \\
1 \\
1 \\
3 \\
1 \\
1 \\
1 \\
3 \\
2 \\
3 \\
1 \\
2 \\
3 \\
2 \\
3 \\
2 \\
3 \\
3 \\
1 \\
3 \\
1 \\
2 \\
2 \\
1 \\
3 \\
3\end{array}$ & $\begin{array}{l}1 \\
4 \\
3 \\
1 \\
2 \\
1 \\
3 \\
2 \\
3 \\
1 \\
1 \\
1 \\
0 \\
1 \\
0 \\
2 \\
2 \\
2 \\
2 \\
3 \\
2 \\
1 \\
0 \\
0 \\
4 \\
1 \\
2 \\
2 \\
3 \\
3 \\
0 \\
1 \\
0 \\
1 \\
1 \\
1 \\
2 \\
2\end{array}$ & $\begin{array}{l}2 \\
2 \\
2 \\
2 \\
2 \\
2 \\
2 \\
2 \\
2 \\
2 \\
2 \\
2 \\
2 \\
2 \\
2 \\
2 \\
2 \\
0 \\
2 \\
2 \\
0 \\
2 \\
1 \\
0 \\
2 \\
2 \\
2 \\
2 \\
1 \\
2 \\
2 \\
2 \\
2 \\
2 \\
1 \\
2 \\
2 \\
2\end{array}$ & $\begin{array}{r}85 \\
63 \\
76 \\
100 \\
72 \\
27 \\
89 \\
49 \\
68 \\
48 \\
8 \\
51 \\
37 \\
24 \\
41 \\
87 \\
7 \\
63 \\
97 \\
64 \\
93 \\
74 \\
58 \\
75 \\
94 \\
100 \\
88 \\
102 \\
102 \\
83 \\
29 \\
106 \\
88 \\
47 \\
18 \\
76 \\
93 \\
9\end{array}$ & $\begin{array}{r}34 \\
100 \\
43 \\
83 \\
47 \\
82 \\
57 \\
66 \\
112 \\
45 \\
59 \\
58 \\
40 \\
42 \\
11 \\
69 \\
51 \\
101 \\
99 \\
36 \\
48 \\
25 \\
62 \\
40 \\
69 \\
61 \\
104 \\
105 \\
74 \\
72\end{array}$ & $\begin{array}{r}55 \\
85 \\
87 \\
91 \\
94 \\
40 \\
104 \\
55 \\
120 \\
78 \\
95 \\
60 \\
41 \\
95 \\
66 \\
100 \\
83 \\
74 \\
39 \\
71 \\
65 \\
117 \\
41 \\
109 \\
63 \\
89 \\
111 \\
137 \\
90 \\
48 \\
82 \\
57 \\
5 \\
63 \\
142 \\
60 \\
94 \\
103\end{array}$ & $\begin{array}{r}19 \\
57 \\
7 \\
53 \\
43 \\
32 \\
77 \\
27 \\
28 \\
58 \\
26 \\
36 \\
18 \\
73 \\
37 \\
62 \\
40 \\
47 \\
25 \\
49 \\
10 \\
22 \\
22 \\
1 \\
51 \\
65 \\
33 \\
1 \\
54 \\
25 \\
39 \\
48 \\
3 \\
34 \\
41 \\
47 \\
33 \\
8\end{array}$ \\
\hline
\end{tabular}

$\star 1=$ Myelum; 2 = cerebral; 3 = spastic paraplegia.

† $0=$ MRC $5 ; 1=$ MRC $4 ; 2=\operatorname{MRC} 2$ or $3 ; 3=$ MRC 0 or 1.

$\neq 1=$ Normal; $2=$ increased; $3=$ clonus. 
flexor in only three patients. The plantar response was therefore not included in the correlation analysis. The only appreciable difference in clinical characteristics between patients with a cerebral lesion, myelopathy, and spastic paraparesis was that paresis was more severe in patients with a myelopathy than in patients with a slowly progressive spastic paraparesis.

CLINICAL SIGNS AND NEUROPHYSIOLOGICAL FEATURES

Table 1 also shows the results of the H-reflex tests. Figure 3 shows vibratory effects in controls and patients grouped according to muscle tone. In the patients a moderate but significant correlation was found between degree of hypertonia and vibratory effects on the $H$-reflex expressed by the cumulative vibratory index $(r=0.46, p<0.01)$. A difference in the index existed between the patients with normal (Ashworth 0, mean 39\%, range $11 \%-61 \%)$ and the ones with moderately elevated tone (Ashworth 2, mean 74\%, range $47 \%-104 \%, p<0.05$ for comparing six pairs of means). Patients with severe hypertonia showed no further increase in the index (mean $70 \%$, range $36 \%-111 \%$ ). The cumulative vibratory index did not correlate with loss of muscle strength $(r=0.14, p=0.40)$ or enhancement of tendon reflexes $(r=0.15$, $\mathrm{p}=0 \cdot 38$ ).

Figure 4 shows $H$ to $M$ ratios in controls and patients grouped according to tendon reflex activity. In the patients a moderately correlated increase of the $\mathrm{H}$ to $\mathrm{M}$ ratio with enhancement of tendon reflex activity was found $(r=0.55, p<0.001)$. In all 13 patients with ankle clonus the $H$ to $M$ ratio was $64 \%$ or greater with a mean value of $88 \%$ (range $64 \%-106 \%$ ), which was significantly more than the mean in patients with normal Achilles tendon reflexes (mean $47 \%$, range $7 \%-96 \%, p<0.01$ for comparing three pairs of means). A weakly correlated increase of the

Figure 3 Correlation between muscle tone and cumulative vibratory index. ${ }^{\star}$ Indicates difference in index between controls and patients with normal tone $(P<0.05)$; **indicates difference in index between patients with normal and patients with moderately elevated tone $(p<0.05$ for comparing six pairs of means); mean (SD).

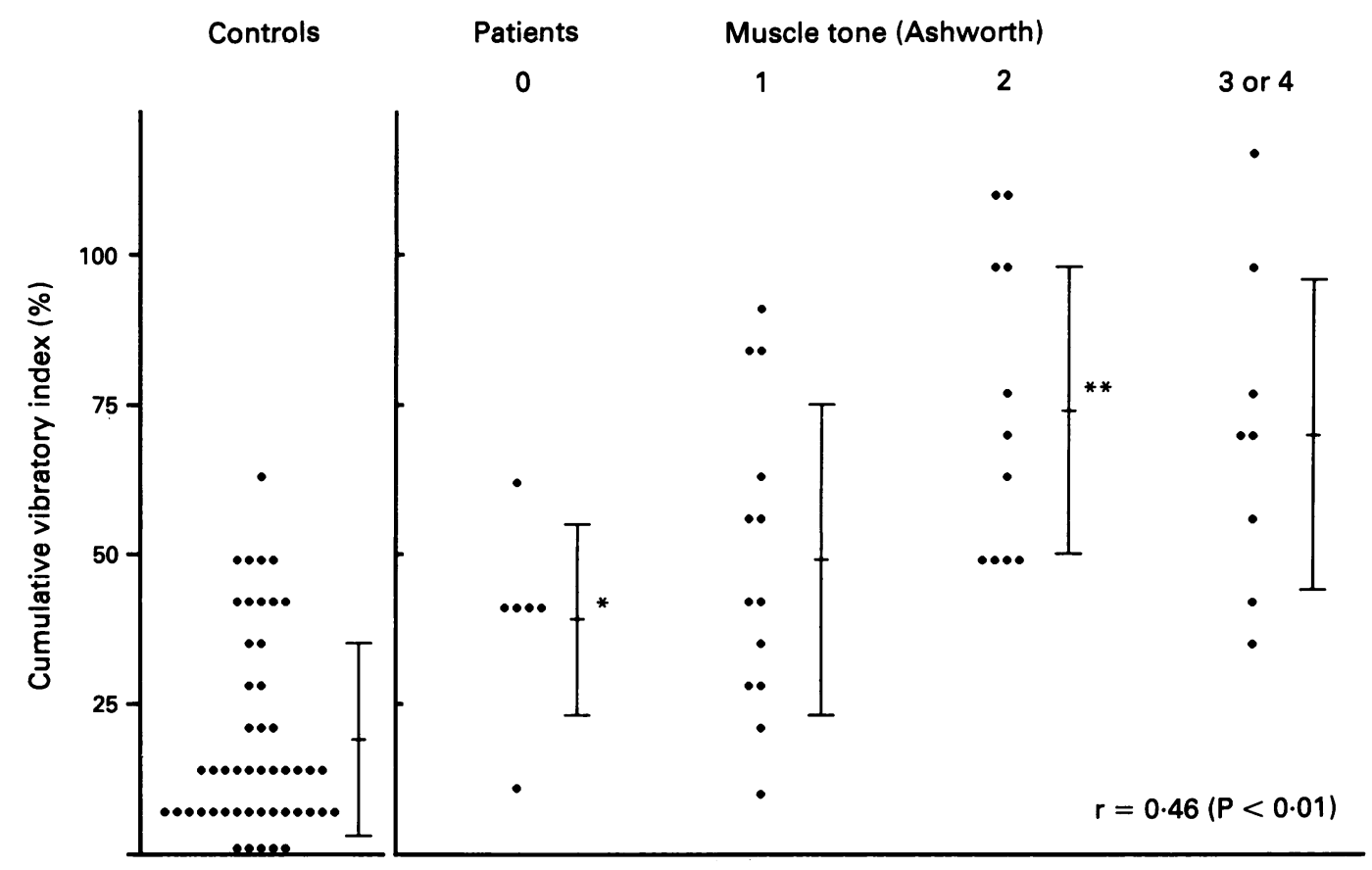

Muscle tone (Ashworth)
$H$ to $M$ ratio with increase of muscle tone was found $(r=0.34, p<0.05)$. There was no relation between the $H$ to $M$ ratio and loss of muscle strength $(\mathrm{r}=-0.16, \mathrm{p}=0.34)$. In patients the $\mathrm{H}$ to $M$ ratio also correlated with age $(r=-0.35, p<0.05)$. When forward stepwise regression analysis was performed with age and tendon reflex activity for the $\mathrm{H}$ to $M$ ratio, however, partial correlation of age was $-0.07(p=0.66)$. Thus the correlation between the $H$ to $M$ ratio and age was almost fully determined by decreased tendon reflex activity found at advanced ages. In the patients a small correlation existed between the $\mathrm{H}$ to $\mathrm{M}$ ratio and the cumulative vibratory index $(r=0.35, p<0.05)$.

Figure 5 shows findings of the late facilitation of the recovery curve in controls and patients grouped according to tendon reflex activity. Late facilitation increased with enhancement of tendon reflex activity ( $r=$ $0.40, p<0.05$ ). In patients with clonus the late facilitation was increased (mean $88 \%$, range $48 \%-117 \%$ ) compared with patients who had normal tendon reflexes (mean $62 \%$, range $5 \%-95 \%, p<0.05$, for comparing three pairs of means). The late facilitation did not correlate significantly with muscle tone ( $r=0.23, p=0.16)$ or loss of muscle strength $(r=0.09, p=0.60)$. In the patients there was no correlation between the $H$ to $M$ ratio and the late facilitation of the recovery curve $(r=0.01, p=0.93)$. The late inhibition did not correlate significantly with tone $(\mathrm{r}=0.25, \mathrm{p}=0.13)$, muscle strength $(\mathrm{r}=$ $0 \cdot 25, p=0 \cdot 13)$, or activity of tendon reflexes $(\mathrm{r}=0.08, \mathrm{p}=0.64)$.

Patients with normal tone or normal tendon reflexes were compared with control subjects. There was no difference in the $\mathrm{H}$ to $M$ ratio in the patients with normal tendon reflexes and the control subjects (mean $48 \%$, range 6\%-99\%) (figure 4 ). In control subjects vibratory effects on the $\mathrm{H}$-reflex (mean $19 \%$, range $0 \%-60 \%$ ) were more pronounced 


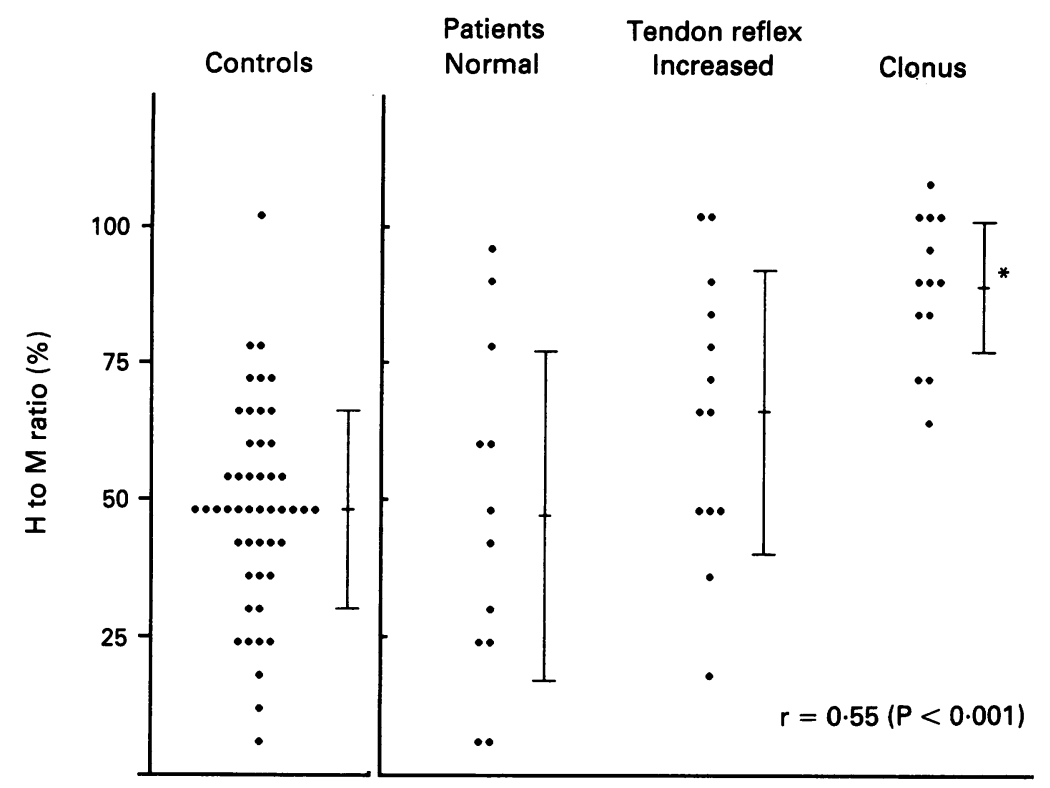

Figure 4 Correlation between tendon reflex activity and $H$ to $M$ ratio. ${ }^{*}$ Indicates difference between $H$ to $M$ ratio in patients with normal tendon reflexes and patients with clonus ( $p<0.01$ for comparing three pairs of means); mean $(S D)$.

$(\mathrm{p}<0.05)$ than vibratory effects in patients with normal tone (figure 3). Late facilitation in patients with normal tendon reflexes (figure 5) was higher than in control subjects (mean $42 \%$, range $8 \%-92 \%, \mathrm{p}<0.05$ ). This was also the case for late inhibition; in patients with normal reflexes the mean was $36 \%$ (range $3 \%-73 \%$ ) and in controls the mean was $17 \%$ (range $2 \%-44 \%, p<0.01$ ).

No significant differences in neurophysiological variables were present between patients with a cerebral lesion, myelopathy, and spastic paraparesis.

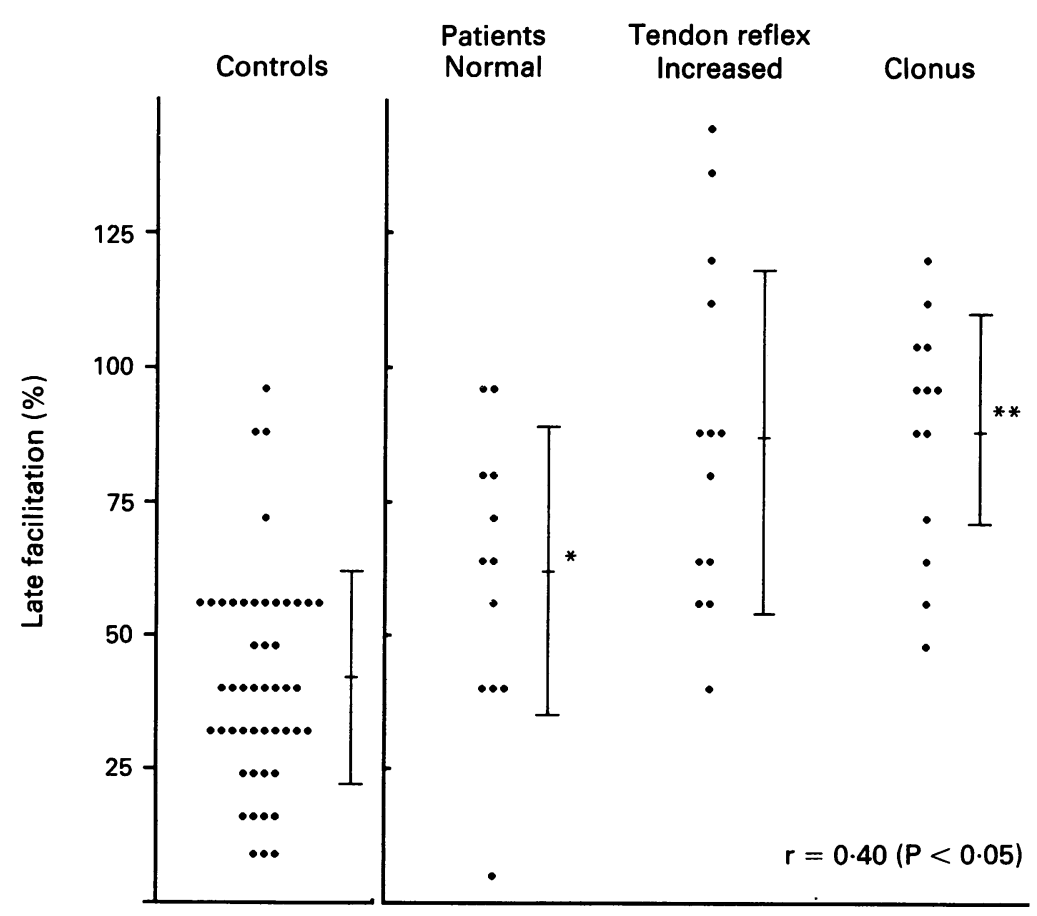

Figure 5 Correlation between tendon reflexes and late facilitation. *Indicates difference between late facilitation in controls and patients with normal tendon reflexes $(p<0.05)$; $\star \star$ indicates difference between patients with normal tendon reflexes and patients with clonus ( $p<0.05$ for comparing three pairs of means); mean (SD).

\section{Discussion}

In healthy subjects vibration of the Achilles tendon, which strongly activates primary spindle endings, suppresses or abolishes the $\mathrm{H}$-reflex for the duration of the vibration. ${ }^{313-16}$ This action is supposed to be predominantly due to an autogenic axoaxonal presynaptic inhibition of Ia terminals, although other mechanisms have been suggested as well..$^{31314^{17-19}}$ In patients with acute spinal or cerebral lesions, flaccid paralysis, and areflexia vibratory inhibition is enhanced, ${ }^{2021}$ whereas in most patients with longer standing lesions and spasticity inhibition of the soleus $\mathrm{H}$-reflex during vibration of the Achilles tendon is decreased. ${ }^{4720-22}$ Studies relating diminished vibratory inhibition to specific clinical signs of the upper motor neuron syndrome are scarce. Delwaide mentioned no relation between the classic vibratory index and muscle tone, but subgroups of spastic patients were small and did not include patients with normal tone and more clinical details were not provided. ${ }^{2}$ On the other hand, Taylor et al found a correlation between vibratory inhibition and spasticity, when spasticity was defined as the combination of hypertonia and hyperreflexia. ${ }^{4}$ Iles and Roberts reported that in a small selected group of patients with upper motor neuron lesions studied during active dorsiflexion of the foot a decrease of suppression of vibratory inhibition correlated more with severity of weakness than with spasticity. ${ }^{23} \mathrm{We}$ found a moderate but significant correlation between vibratory inhibition and hypertonia. In contrast to other studies our cumulative measurement of vibratory effects integrates the vibratory inhibition at multiple stimulus intensities. It seems to have some greater discriminative power ${ }^{5}$ than the classic ratio between the maximum $\mathrm{H}$-reflex response and maximum muscle potential. ${ }^{3}$ Our findings may indicate a quantitative relation between decrease of tonic regulation of presynaptic inhibition and increase of muscle tone up to moderate levels. Decrease of presynaptic inhibition could result in an increased afferent input to the soleus motor neuron pool contributing to enhanced resistance to passive stretch characteristic of hypertonia. ${ }^{24}$ As such our findings would support the view that hypertonia is associated with the release of a central gain controlling mechanism in which the ability to modulate reflex transmission is lost. ${ }^{25}$

Although there are differences in electrically and mechanically elicited reflexes, ${ }^{26}$ a positive correlation between the $\mathrm{H}$ to $\mathrm{M}$ ratio and enhancement of tendon reflex activity was found. The $H$ to $M$ ratio correlated to a lesser degree with muscle tone. Clearly enlarged $\mathrm{H}$ to $M$ ratios were found in all patients with clonus and probably indicate that in clonus enhancement of motor neuron excitability is generally present. These results could be accounted for by mechanisms other than direct increases in motor neuron excitability, as, for example, increases in transmission through the stretch reflex arc secondary to 
reduced presynaptic inhibition on 1a afferent terminals.

Postsynaptic late facilitation in the recovery curve correlated slightly with enhancement of tendon reflex activity, independently of increased $\mathrm{H}$ to $\mathrm{M}$ ratios. Late facilitation occurs at time intervals of about $250 \mathrm{~ms}$ between the conditioning and the test stimulus and is followed by a late inhibitory period at stimulus time intervals up to 1 second and afterwards by complete recovery of $\mathrm{H}$-reflex features. ${ }^{27} 28$ The late facilitation may be partly due to cutaneous afferents. ${ }^{29} 30$ Its potentiation in spasticity, Parkinsonian rigidity, and dystonia ${ }^{6730-33}$ suggests that the polysynaptic pathways are affected, either in the spinal cord or along long-loop pathways. ${ }^{33}$ Potentiation of late facilitation in patients with an upper motor neuron syndrome seems unrelated to altered tone, ${ }^{32}$ unlike that which is thought to occur in dystonia. ${ }^{73}$ In clonus, however, the late facilitation was elevated. Thus in clonus interneuronal hyperactivity and increased motor neuron excitability may be combined. Both are consistent with conclusions based on direct recordings from Ia afferents, that spinal mechanisms rather than increased fusimotor drive are involved in clonus. ${ }^{34}$

In our study we found that in patients with the upper motor neuron syndrome alterations in results of the soleus H-reflex test may occur independently from each other to a large extent and that they relate to specific clinical features of the upper motor neuron syndrome. The fact that our findings were obtained in a heterogenous groups of patients may validate our results. We cannot, however, fully exclude the possibility that alterations in the tests are influenced more by underlying pathology than clinical characteristics. Further studies in distinct groups of patients with the same kind of upper motor neuron disease are necessary to clarify this.

We thank AAM Hart from the laboratory of medical physics for his advice on the statistical analysis of data, DA Kropveld for computer assistance, Dr J Stam for his helpful suggestions and careful reading of the manuscript.

JHTMK was supported by a grant from the Prinses Beatrix Fonds, AAJH was supported by the Netherlands Organization for Scientific Research (NWO).

1 Schieppati M. The Hoffmann reflex: a means of assessing spinal reflex excitability and its descending control in man. Prog Neurobiol 1987;28:345-76.

2 Delwaide PJ. Contribution of human reflex studies to the understanding and management of the pyramidal syndrome. In: Shahani BT, ed. Electromyography in CNS disorders: central EMG. Boston: Butherwords, 1984 77-109.

3 Delwaide PJ. Human monosynaptic reflexes and presynaptic inhibition; an interpretation of spastic hyperreflexia. In: Desmedt JE, ed. New developments in electromyography and clinical neurophysiology. Vol 3. Basel: Karger, 1973:508-22.

4 Taylor S, Ashby P, Verrier M. Neurophysiological changes following traumatic spinal lesions in man changes following traumatic spinal lesions
f Neurol Neurosurg Psychiatry 1984;47:1 102-8.

F Neurol Neurosurg Psychiatry 1984;47:1102-8.
5 Ongerboer de Visser BW, Bour LJ, Koelman JHTM Speelman JD. Cumulative vibratory indices and the $\mathrm{H} / \mathrm{M}$ ratio of the soleus $\mathrm{H}$-reflex: a quantitative study in $\mathrm{H} / \mathrm{M}$ ratio of the soleus $\mathrm{H}-$-reflex: a quantitative study in
control and spastic subjects. Electroencephalogr Clin control and spastic subjects.

6 Sax DS, Johnson TL. Spinal reflex activity in man, measurement in relation to spasticity. In: Feldman RG
Young, RR, Koella WP, eds. Spasticity: disordered motor Young, RR, Koella WP, eds. Spasticity: disordered

7 Bour LJ, Ongerboer de Visser BW, Koelman JHTM, van Bruggen GJ, Speelman JD. Soleus H-reflex tests in spasticity and dystonia: a computerized analysis. Fournal of Electromyography and Kinesiology 1991;1:9-19.

8 Dohrmann GJ, Nowack WJ. Relationship between various clinical signs in lesions of the descending motor system. Diseases of the nervous system 1974;35:375-7.

9 Ashworth B. Preliminary trial of carispodol in multiple sclerosis. Practitioner 1964;192:540-2.

10 Medical Research Council. Aids to the examination of the peripheral nervous system. London: HMSO, 1976:6-7. peripheral nervous

11 Hugon M. Methodology of the Hoffmann reflex in man. In: Desmedt JE, ed. New developments in electromyography and clinical neurophysiology Vol 3. Basel: Karger, 1973:277-93.

12 Boxtel A van. Differential effects of low-frequency depression, vibration-induced inhibition and posttetanic potentation on $\mathrm{H}$-reflexes and tendon jerks in the human soleus muscle. I Neurophsyiol 1986;55:551-68.

13 DeGail P, Lance JW, Neilson PD. Differential effects on tonic and phasic reflex mechanisms produced by vibration of muscles in man. $f$ Neurol Neurosurg Psychiatry 1966;29:1-11.

14 Delwaide PJ. Etude expérimentale de 1'hyperréflexie tendineuse en clinique neurologique. Bruxelles: Arscia, 1971.

15 Hagbarth KE, Eklund G. The effect of muscle vibration in spasticity, rigidity and cerebellar disorders. $\mathcal{F}$ Neurol Neurosurg Psychiatry 1968;31:207-13.

16 Matthews PBC. Evidence from the use of vibration that the human long-latency stretch reflex depends upon spindle secondary afferents. $f$ Physiol 1984;348: 383-415.

17 Gillies JD, Lance JW, Neilson PD, Tassinari CA. Presynaptic inhibition of the monosynaptic reflex by vibration. F Physiol 1969;205:329-39.

18 Burke D, Ashby P. Are spinal "presynaptic" inhibitory mechanisms suppressed in spasticity? $f$ Neurol Sci 1972;15:321-6.

19 Hultborn H, Meunier S, Morin C, Pierrot-Deseilligny E. Assessing changes in presynaptic inhibition of la fibres: a Assessing changes in presynaptic inhibition of la fibres:

20 Ashby P, Verrier M, Lightfoot E. Segmental reflex pathways in spinal shock and spinal spasticity in man. ways in spinal shock and spinal spasticity
$¥$ Neurol Neurosurg Psychiatry 1974;37:1352-60.

21 Ashby P, Verrier M. Neurophysiologic changes in hemiplegia. Neurology 1976;26:1145-51.

22 Hayat A. Factorial analysis of specific parameters in spasticity. Electromyogr Clin Neurophysiol 1979;19:541-53.

23 Iles JF, Roberts RC. Presynaptic inhibition of monosynaptic reflexes in the lower limbs of subjects with upper motor neuron disease. $\mathcal{F}$ Neurol Neurosurg Psychiatry 1986;49:937-44.

24 Ashby P, Verrier M, Carleton S. Vibratory inhibition of the monosynaptic reflex. In: Desmedt JE, ed. Spinal and supraspinal mechanisms of voluntary motor control and locomotion. (Progress in Clinical Neurophysiology, vol 8.) Basel: Karger, 1980:254-62.

25 Burke D. A reassessment of the muscle spindle contribution to muscle tone in normal and spastic man. In: Feldman RG, Young RR, Koella WP, eds. Spasticity: disordered motor control. Miami: Symposia Specialists, 1980:261-77.

26 Burke D, Mechanisms underlying the tendon jerk and H-reflex. In: Delwaide PJ, Young RR, eds. Clinical neurophysiology in spasticity Amsterdam: Elsevier, 1985: 55-62.

27 Magladery JW, Teasdall RD, Park AM, Languth HW. Electrophysiological studies of the $\mathrm{H}$-reflex activity in patients with lesions of the nervous system. I. A comparison of spinal motoneurone excitability following afferent nerve volleys in normal persons and patients with upper motoneurone lesions. Bulletin of the fohns with upper motoneurone lesions.

28 Paillard J. Reflexes et regulations d'origine proprioceptive chez l'homme. Paris: Librairie Arnette, 1955. (Thesis)

29 Gassel MM. A critical review of evidence concerning long-loop reflexes excited by muscle afferents in man I Neurol Neurosurg Psychiatry 1970;33:358-62.

30 Pierrot-Deseilligny E, Bussel B, Morin C. Supraspinal control of the changes induced in $\mathrm{H}$-reflex by cutaneous stimulation, as studied in normal and spastic man. In: Desmedt JE, ed. New Developments in electromyography and clinical neurophysiology. Vol 3. Basel: Karger, 1973:550-5.

31 Yap CB. Spinal segmental and long-loop reflexes on spinal motoneurone excitability in spasticity and rigidity. Brain 1967;90:887-96.

32 Zander Olsen P, Diamantopoulos E. Excitability of spinal motor neurones in normal subjects and patients with spasticity, Parkinsonian rigidity, and cerebellar hypotonia. F Neurol Neurosurg Psychiatry 1967;30:325-31.

33 Panizza M, Lelli S, Nilsson J, Hallet $M$. H-reflex recovery curve and reciprocal inhibition of $\mathrm{H}$-reflex in different curve and reciprocal inhibition of H-reflex
kinds of dystonia. Neurology 1990;40:824-8.

34 Haghbarth KE, Wallin G, Lofstedt L Aquilonius SM Muscle spindle activity in alternating tremor of Muscle spindle activity in alternating tremor of
Parkinsonism and in clonus. $\mathcal{F}$ Neurol Neurosurg Psychiatry 1975;38:636-41. 